\title{
Logistics Needs for Potential Deep Space Mission Scenarios Post Asteroid Redirect Crewed Mission
}

\author{
Pedro Lopez Jr. \\ and Eric Schultz \\ NASA Johnson Space Center \\ 2101 NASA Pkwy \\ Houston, TX 77058 \\ 281-483-7124 \\ pedro.lopez-1@nasa.gov \\ 281-244-7866 \\ eric.d.schultz@nasa.gov
}

\author{
Bryan Mattfeld \& Chel Stromgren \\ Binera, Inc. \\ 8455 Colesville Road, Suite 1075 \\ Silver Spring, MD 20910 \\ 301-579-5242 \\ b.mattfeld@binera.com, \\ c.stromgren@binera.com
}

\author{
Kandyce Goodliff \\ NASA Langley Research Center \\ Hampton, VA 23681 \\ 757-864-4969 \\ kandyce.e.goodliff@nasa.gov
}

\begin{abstract}
The Asteroid Redirect Mission (ARM) is currently being explored as the next step towards deep space human exploration, with the ultimate goal of reaching Mars. NASA is currently investigating a number of potential human exploration missions, which will progressively increase the distance and duration that humans spend away from Earth. Missions include extended human exploration in cis-lunar space which, as conceived, would involve durations of around 60 days, and human missions to Mars, which are anticipated to be as long as 1000 days. The amount of logistics required to keep the crew alive and healthy for these missions is significant. It is therefore important that the design and planning for these missions include accurate estimates of logistics requirements.
\end{abstract}

This paper provides a description of a process and calculations used to estimate mass and volume requirements for crew logistics, including consumables, such as food, personal items, gasses, and liquids. Determination of logistics requirements is based on crew size, mission duration, and the degree of closure of the environmental control life support system (ECLSS).

Details are provided on the consumption rates for different types of logistics and how those rates were established. Results for potential mission scenarios are presented, including a breakdown of mass and volume drivers. Opportunities for mass and volume reduction are identified, along with potential threats that could possibly increase requirements.

\section{TABLE OF CONTENTS}

1. INTRODUCTION .1

2. CANDidate Missions. .2 3. METHODOLOGY AND GENERAL ASSUMPTIONS 2 4. CaSe Results and Mass BREaKdown .........5 5. LOGISTICS OPPORTUNITIES \& THREATS .........7 6. CONCLUSIONS .....................................................8 ACKNOWLEDGEMENTS..........................................9 REFERENCES.......................................................9 BIOGRAPHY .............................................................

\section{INTRODUCTION}

NASA is currently investigating a number of candidate exploration missions that travel to destinations beyond Low Earth Orbit (LEO). These missions include a progressive increase in the time that humans will be required to spend

U.S. Government work not protected by U.S. copyright away from Earth vicinity. Potential mission scenarios range from human exploration of cis-lunar space, requiring durations of around 60 days, to Mars destination exploration, requiring mission durations of up to 1000 days or more.

The amount of consumables required to maintain crew health and survival during such missions is substantial. The supply of adequate logistics can become a first-order driver in mission design. Increasing distances from Earth and longer mission durations will limit, or entirely restrict, crew access to Earth supply chains. For cis-lunar missions, crew logistics must be supplied to lunar vicinity for each crewed increment. For Mars missions, it is assumed that all logistics payloads required to support the crew must be manifested within the initial Deep Space Vehicle (DSV). Thus, it is vital that the design and planning of proposed missions include accurate estimates of crew logistics requirements.

This study presents a detailed review of the crew logistics requirements necessary to support crew exploration missions that extend into deep space. A consumables model was developed to estimate logistics based on characteristics such as crew size, mission duration, consumables usage rates, and degree of ECLSS closure. Storage requirements are assessed as well, providing estimates for the expected overhead mass and volume required to deliver and store materials.

It should be noted that the results presented in this paper are for logistics and consumables related to the crew only. Although not evaluated as part of this effort, it is expected that spares and maintenance items associated with the spacecraft will also present substantial mass and volume requirements. In addition, the analysis presented herein is only for basic operations required to keep the crew alive and healthy. Additional operations, such as Extra Vehicular Activity (EVA), science, and other types of utilization will increase logistics requirements. Ultimately, the spacecraft will have to accommodate logistics requirements for all applications.

Section 2 of this paper describes two candidate exploration missions that are evaluated as part of this assessment: a shorter duration cis-lunar mission and long duration Mars destination mission. A comprehensive description of the methodology and assumptions used in the logistics model is then presented in Section 3. This section includes 
descriptions of ECLSS performance assumptions, crew usage rates, packaging constraints, and fluid and gas storage requirements. Section 4 contains baseline results for the crew logistics needs. Finally, several opportunities to reduce logistics requirements are identified and discussed, and final conclusions are presented.

\section{Candidate Missions}

The Asteroid Redirect Crewed Mission (ARCM) concept, as it currently stands, envisions the use of the Space Launch System (SLS) and Orion spacecraft to send a crew of two astronauts to investigate asteroid material previously redirected to a Lunar Distant Retrograde Orbit (LDRO) by the Asteroid Redirect Robotic Vehicle (ARRV) and return samples to Earth [1]. The ARCM concept includes a five-day stay at the LDRO with a maximum mission duration of 30 days, enabling two 4-hour Extra-Vehicular Activities (EVAs) to obtain the samples. The mission duration and crew size were limited to 30 days and 2 astronauts, respectively, to maintain required crew consumables within the Orion capabilities in the Exploration Mission-2 (EM-2) configuration. The Orion EM-2 configuration is being designed to support a crew of 4 for up to 21 days.

Building from the capabilities and operations that would be tested in ARCM, various mission concepts are being assessed. To ensure mission success, the design of mission concepts must include allocations for the logistics required to sustain the crew, including their mass and volume. To demonstrate the variability in requirements, two missions were analyzed. Requirements for alternate specific mission concepts will vary based on assumed crew size and mission duration.

\section{Cis-Lunar Crewed Mission}

The mission concept that was evaluated for this paper includes an increase in crew size to four astronauts and extended durations in the LDRO for asteroid exploration of up to 60 days. It is anticipated that an additional habitation module would be utilized, in conjunction with the Orion spacecraft, to provide the additional volume and storage for logistics and the systems necessary to support the longer durations. It is assumed that the habitation module would provide the ECLSS functions required, with Orion providing waste management (commode and urinal), $\mathrm{CO}_{2}$ removal, as well as the pantry. Logistics would have to be re-supplied to the cis-lunar habitat for each 60-day crew stay. The integrated stack is also assumed to include a logistics module.

\section{Crewed Mission to Mars}

NASA is also assessing potential crewed missions to Mars [2]. These assessments include an array of possible Mars destinations - Mars moons Phobos and Deimos, Mars orbit, and Mars surface. Long duration habitation will be required to transport the crew to and from Mars vicinity. It is assumed that, for this mission concept, the deep space vehicle (DSV) will need to have the capability to store and allow access to all logistics required for the mission. A crew of four was assumed for the human Mars mission. Specific Mars mission durations will vary based on the opportunity. For the purposes of this analysis, the transit time was assumed to be 600 days and the Mars vicinity time was assumed to be 400 days. In the analysis presented in this paper, it is assumed that logistics must be carried in the DSV for the entire 1000 day period. Most candidate Mars missions assume that the crew transfers to the Mars surface or to another destination (such as Phobos) for at least part of the time the crew is in Mars vicinity and that logistics for those segments would be preemplaced. However, it was assumed that for contingency purposes, the DSV must be capable of supporting the crew for the entire duration, in case the crew is not able to reach the intended destination and must remain in the DSV for the entire mission. A contingency period of 30 days is also added to the total duration to account for uncertainties in consumption and duration and to protect against down time of equipment due to maintenance or repair. The integrated stack is assumed to include a second module representing a logistics module/carrier. Lastly, it is assumed that the Orion is not included in the integrated stack.

\section{METHOdOLOGY AND GENERAL ASSUMPTIONS}

The present study includes an assessment of required consumables and crew provisions, associated packaging, and waste management items. Other components that may need to be delivered logistically such as spare parts, science instrumentation, as well as EVA hardware and consumables, are not included in this study. These items, which will be dependent on specific mission goals and the design of spacecraft systems, will require additional mass and volume allocations.

Crew logistics mass and volume requirements are dependent upon a number of factors, including: crew size, mission duration, and ECLSS system design. NASA has developed a comprehensive model to evaluate all logistics items associated with the crew that takes into account all relevant factors. The model uses standard usage rates and packaging factors that are derived from historical spaceflight data or taken from NASA standards documents. The model includes an operational analysis of the ECLSS system.

\section{Usage rates}

Crew consumption rates for all logistics goods were defined using International Space Station (ISS) historical usage and resupply rates in combination with data from the Advanced Life Support Baseline Values and Assumptions Document (BVAD) [3], the Human Integration Design Handbook (HIDH) [4], and Orion/Commercial Crew Development (CCDev) design values. Derived values were reviewed for accuracy by ECLSS community experts and NASA's Advanced Exploration System (AES) community. Where appropriate, these derived values were refined to best reflect the expected performance of future exploration class habitation systems. Usage rates used in this assessment represent a current "best estimate" for future exploration 
systems. It is anticipated that these estimates may change in the future as NASA refines mission designs.

Food and Crew Provisions - Table 1 provides the rates used in the logistics model for food and crew provision requirements. The rate for most items are specified per mission crew day. Certain other items are specified per day or per crew (irrespective of mission length).

A standard requirement of $1.831 \mathrm{~kg}$ per crew day is used as the supply rate for food, as cited in the BVAD. This rate includes individual meal packaging and some degree of margin in the amount of food to account for variability in individual meal consumption. Although the supply rate includes packaging, food must still be packed in other carriers for launch and storage.

The clothing rate of $0.22 \mathrm{~kg}$ per crew day represents an average usage of clothing over time. Individual items of clothing are consumed at different rates, based upon their usage life.

Table 1 - Usage Rates for Food and Crew Provisions

\begin{tabular}{|l|l|c|l|}
\multicolumn{1}{c}{ Food/Crew Provisions } \\
\hline \multicolumn{1}{|c|}{ Item } & \multicolumn{1}{c|}{ Units } & Rate & \multicolumn{1}{c|}{ Notes } \\
\hline Food & Kg/crew/day & 1.831 & $\begin{array}{l}\text { BVAD Table \& ISS } \\
\text { experience }\end{array}$ \\
\hline $\begin{array}{l}\text { Waste Collection } \\
\text {-Fecal Canisters }\end{array}$ & Kg/day & 0.9 & Orion values \\
\hline $\begin{array}{l}\text { Waste Collection } \\
\text { - Urine Pre-filter }\end{array}$ & Kg/day & 0.25 & Orion values \\
\hline $\begin{array}{l}\text { Personal Hygiene } \\
\text { Kit }\end{array}$ & $\mathrm{kg}$ per crew & 1.8 & $\begin{array}{l}\text { ISS value; used for every } \\
\text { six months }\end{array}$ \\
\hline $\begin{array}{l}\text { Hygiene } \\
\text { Consumables }\end{array}$ & Kg/crew/day & 0.079 & $\begin{array}{l}\text { Match Orion WCS } \\
\text { Supplies Value }\end{array}$ \\
\hline $\begin{array}{l}\text { Clothing (No } \\
\text { Laundry) }\end{array}$ & Kg/crew/day & 0.22 & Recent ISS data \\
\hline $\begin{array}{l}\text { Recreation \& } \\
\text { Personal } \\
\text { Stowage }\end{array}$ & $\mathrm{kg}$ per crew & $25 / 50$ & $\begin{array}{l}25 \mathrm{~kg} \leq 1 \mathrm{yr} ; \\
50 \mathrm{~kg}>1 \mathrm{yr} .\end{array}$ \\
\hline Wipes \& Towels & $\mathrm{Kg} / \mathrm{crew} /$ day & 0.195 & $\begin{array}{l}\text { AES trash team / ISS } \\
\text { historical data }\end{array}$ \\
\hline Trash Bags & Kg/crew/day & 0.011 & $\begin{array}{l}\mathrm{AES} \text { trash team / ISS } \\
\text { historical data }\end{array}$ \\
\hline $\begin{array}{l}\text { Operational } \\
\text { Supplies }\end{array}$ & $\mathrm{kg}$ per crew & $20 / 25$ & $\begin{array}{l}20 \mathrm{~kg} \leq 1 \mathrm{yr} ; \\
25 \mathrm{~kg}>1 \text { yr. }\end{array}$ \\
\hline $\begin{array}{l}\text { Health Care } \\
\text { Consumables }\end{array}$ & Kg/crew/day & 0.09 & $\begin{array}{l}\text { AES trash team / ISS } \\
\text { historical data }\end{array}$ \\
\hline
\end{tabular}

Water and Gas-The logistics model that was used for this assessment evaluates the amounts of water and gas that must be utilized in order to keep the crew alive and healthy. The model also simulates the operation of the Environmental Control and Life Support System (ECLSS) in the crew habitat and, if applicable, its ability to recycle water and carbon dioxide.

The basic water consumption rates used for drinking, food preparation, medical, flush, and hygiene are presented in Table 2. These usage rates represent the average amount of water that is consumed by crew. All rates are based on standard values from the NASA HIDH and the Advanced Life Support BVAD. The rates used in this study do not account for the initial amount of operating water and gas that is present in the ECLSS system.

Table 2 - Water Consumption and Recovery Rates

\begin{tabular}{|c|c|c|c|}
\hline \multicolumn{4}{c}{ Water Usage } \\
\hline Item & Units & Rate & Notes \\
\hline $\mathrm{H}_{2} \mathrm{O}$ Drink & kg per crewday & 2 & BVAD/HIDH \\
\hline $\begin{array}{c}\mathrm{H}_{2} \mathrm{O} \text { Food } \\
\text { Rehydration }\end{array}$ & kg per crewday & 0.5 & BVAD/HIDH \\
\hline $\mathrm{H}_{2} \mathrm{O}$ Medical & kg per crewday & 0.05 & BVAD/HIDH \\
\hline $\mathrm{H}_{2} \mathrm{O}$ Hygiene & kg per crewday & 0.4 & BVAD/HIDH \\
\hline $\mathrm{H}_{2} \mathrm{O}$ Flush & kg per day & 0.25 & BVAD/HIDH \\
\hline
\end{tabular}

\begin{tabular}{|c|c|c|c|}
\hline Water Recovery \\
\hline Item & Units & Rate & $\begin{array}{c}\text { Percent } \\
\text { Recoverable }\end{array}$ \\
\hline Crew Latent & kg per crewday & 1.87 & 100 \\
\hline Urine & kg per crewday & 1.49 & 85 \\
\hline Flush & kg per day & 0.25 & 85 \\
\hline $\mathrm{H}_{2} \mathrm{O}$ Hygiene & kg per crewday & 0.4 & 100 \\
\hline $\mathrm{H}_{2} \mathrm{O}$ Medical & kg per crewday & 0.05 & 100 \\
\hline
\end{tabular}

Table 3 presents the gas usage rates for human missions. These values include both metabolic oxygen consumption by the crew and other normal losses of air in the spacecraft that would require resupply. Metabolic oxygen consumption is based on BVAD data, while leakage rates are based on engineering estimates and are applied per element. Leakage rates for Orion are used on missions where Orion is present. Orion swing bed air loss rates, which represent air loss via operation of the Orion $\mathrm{CO}_{2}$ removal system, are used when that system is in operation.

Table 3 - Oxygen and Nitrogen Usage Rates

\begin{tabular}{|c|c|c|c|}
\hline Item & Units & Rate & Notes \\
\hline $\mathrm{O}_{2}$ Metabolic & $\mathrm{kg}$ per crew/day & 0.82 & HIDH/BVAD \\
\hline $\begin{array}{c}\text { Swing Bed } \\
\text { Ullage Air Loss }\end{array}$ & $\mathrm{kg}$ per day & 0.122 & $\begin{array}{c}\text { Used only if } \\
\text { Orion is } \\
\text { docked }\end{array}$ \\
\hline $\begin{array}{c}\text { Cabin Air } \\
\text { Leakage }\end{array}$ & $\mathrm{kg}$ per day & 0.00454 & $\begin{array}{c}\text { Engr. } \\
\text { Estimate }\end{array}$ \\
\hline $\begin{array}{c}\text { Cabin Air } \\
\text { Leakage } \\
\text { Orion }\end{array}$ & $\mathrm{kg}$ per day & 0.00908 & $\begin{array}{c}\text { Only if Orion } \\
\text { is docked }\end{array}$ \\
\hline $\begin{array}{c}\mathrm{N}_{2} / \mathrm{O}_{2} \text { Tank } \\
\text { Ullage }\end{array}$ & $\mathrm{kg}$ per tank & 0.5 & Orion/CCDev \\
\hline
\end{tabular}

Oxygen resupply can be provided in two ways, $\mathrm{O}_{2}$ can be delivered, either as pure $\mathrm{O}_{2}$ or in an air mixture, or oxygen can be generated from water via electrolysis, using an oxygen generation system. If an $\mathrm{O}_{2}$ generation system is used, $1.125 \mathrm{~kg}$ of water is required for every $\mathrm{kg}$ of $\mathrm{O}_{2}$ produced. Based on the assumptions made in this study for the Mars 
case, $0.92 \mathrm{~kg}$ of water per crew day would be required to generate the necessary $\mathrm{O}_{2}$.

For water and oxygen, the net amount of logistics that is required is directly related to the degree of closure that is provided by the Environmental Control and Life Support System (ECLSS) in the habitat. "Open-loop" ECLSS typically refers to systems that do not recycle any water or carbon dioxide and therefore necessitate resupply of all required water and oxygen. "Closed-loop" systems include some degree of water recovery and/or carbon dioxide reduction. Recycling water and carbon dioxide reduces the total amount of water and oxygen that must be supplied for the crew. The logistics model specifically accounts for the degree of ECLSS closure in both the water and oxygen systems to estimate net logistics requirements.

For the purposes of this assessment, a series of assumptions are made as to the degree of closure provided by the ECLSS system. Table 2 outlines the amount of water recovered from the crew and the assumed recovery rates used for "closedloop" ECLSS systems for the example human Mars mission. For this assessment, the 30-day contingency period is assumed to operate in an open-loop condition. This is to allow the crew time to repair the ECLSS system, if necessary.

The water recovery system in this study is assumed to recover $100 \%$ of water collected as condensate from perspiration and respiration, along with waste water used from hygiene and medical uses. In addition, waste water from urine and flush water are recovered at $85 \%$.

In addition to the water recovery, it is assumed that the closed-loop ECLSS recovers the metabolic $\mathrm{CO}_{2}$ expired by the crew, at a rate of $1.11 \mathrm{~kg}$ per crew day. For this assessment, it was assumed that a Sabatier system, similar to the one operating on ISS, would be used to reduce the $\mathrm{CO}_{2}$, producing water (and methane). The Sabatier process relies on the use of hydrogen produced as a byproduct of the oxygen generation process. Generally, the amount of $\mathrm{CO}_{2}$ that can be recovered is limited by the availability of hydrogen. Under the assumptions used in this analysis, $0.46 \mathrm{~kg}$ of water can be recovered per crew day from $\mathrm{CO}_{2}$ removed from the atmosphere, limited by the amount of hydrogen available from the electrolysis. This represents a reduction of approximately $51 \%$ of the $\mathrm{CO}_{2}$ recovered. It is possible that a larger amount of water could be recovered, if the $\mathrm{O}_{2}$ generation is increased to account for EVAs, additional leakage, or other uses not captured in this assessment. It is also possible to increase the amount of water recovery through the use of other technologies, but these types of systems were not included in this analysis.

Although overall water recovery rates are less than $100 \%$ for the assumed ECLSS system, there is a net surplus of water produced. This surplus occurs because additional water is added to the system in the form of water in the food that the crew consumes. Although the food is "dehydrated" it still contains approximately $28 \%$ water. The result is that, under the assumptions made for the study, no additional water needs to be added to satisfy water or oxygen generation requirements. Further closure of the ECLSS system will not reduce total logistics requirements.

\section{Logistics Packaging and Overhead}

The mass and volume of the actual logistics items accounts for only a portion of the total mass and volume required for logistics. There are also "overhead" mass and volume requirements that account for delivery and storage containers, packaging materials, and inefficiencies in packing.

All "solid" logistics elements (i.e. anything that is not a gas or liquid) are assumed to be delivered and stored using standard Cargo Transfer Bags (CTBs). These types of bags have been used extensively in the Space Shuttle and ISS programs to deliver and store materials. A standard "single" CTB has an external volume of $0.053 \mathrm{~m}^{3}$. This "single" unit is used as a metric to measure volumetric requirements, and is referred to as a Cargo Transfer Bag Equivalent (CTBE). Actual CTBs come in a variety of sizes, but each is referenced relative to the CTBE volume. A typical mission will include the use of a mix of bag sizes including "half", "single", "double", and "triple" CTBs.

For the purposes of this study, standard overhead packaging rates were established, based upon the use of a mix of bag sizes. Historical ISS delivery data was used to establish a typical ratio of bag types. The mass of each type of bag was then weighted to produce an average bag mass per CTBE of $1.56 \mathrm{~kg}$. Each CTBE can store a maximum of $27.2 \mathrm{~kg}$ of goods, although, in many cases, the amount of loaded cargo is limited by the volume of the bag. For each type of logistic item, historical ISS data was used to establish an average "as loaded" density. The loaded density values used in this study are presented in Table 4.

Table 4 - Consumable Packing Densities

\begin{tabular}{|c|c|}
\hline Item & $\begin{array}{c}\text { "As Loaded” Density } \\
\left(\mathbf{k g} / \mathbf{m}^{3}\right)\end{array}$ \\
\hline Food & 306 \\
\hline $\begin{array}{c}\text { Waste Collection - } \\
\text { Fecal Canisters }\end{array}$ & 186 \\
\hline $\begin{array}{c}\text { Waste Collection - } \\
\text { Urine Pre-filter }\end{array}$ & 186 \\
\hline $\begin{array}{c}\text { Personal Hygiene } \\
\text { Kit }\end{array}$ & 186 \\
\hline $\begin{array}{c}\text { Hygiene } \\
\text { Consumables }\end{array}$ & 186 \\
\hline $\begin{array}{c}\text { Clothing } \\
\text { Recreation \& } \\
\text { Personal Stowage }\end{array}$ & 235 \\
\hline Wipes & 186 \\
\hline Trash Bags & 186 \\
\hline $\begin{array}{c}\text { Operational } \\
\text { Supplies }\end{array}$ & 235 \\
\hline $\begin{array}{c}\text { Health Care } \\
\text { Consumables }\end{array}$ & 186 \\
\hline
\end{tabular}


These densities account for real-world inefficiencies of packing materials into CTBs, including voids and volume required for foam protection. Foam packaging is assumed to add $1.5 \%$ to the total mass of packed logistics.

The packing densities were utilized along with mass and volume limits of $26.8 \mathrm{~kg}$ and $0.0486 \mathrm{~m}^{3}$, respectively, to determine the number of CTBEs required for each logistics item. The number of CTBEs for the various consumable items were then combined based on compatibility and similar packing density, and then rounded up to 0.5 (i.e.., a "half" CTB). The consumables were grouped as follows: food; fecal canisters, urine pre-filters, and trash bags; personal hygiene kit, hygiene consumables, wipes \& towels, and health care consumables; clothing; and lastly, recreation \& personal stowage and operational supplies.

For this study, all water is assumed to be delivered and stored in Russian-designed Rodnik tanks. These tanks have been used extensively on the ISS. Each tank has a mass of $35 \mathrm{~kg}$ and can store up to 210 liters $(\mathrm{kg})$ of water, requiring $0.21 \mathrm{~m}^{3}$ of volume. Gases $\left(\mathrm{O}_{2}\right.$ and $\left.\mathrm{N}_{2}\right)$ are assumed to be stored in ISS Nitrogen/Oxygen Recharge System (NORS) tanks. These tanks are high-pressure composite overwrap pressure vessels (COPVs) that have a mass of $74.8 \mathrm{~kg}$ and can store up to $38 \mathrm{~kg}$ of $\mathrm{O}_{2}$ or $29 \mathrm{~kg}$ of $\mathrm{N}_{2}$, occupying $0.39 \mathrm{~m}^{3}$ of volume.

Water bag and tank capacity limits are used to determine how many bags/tanks are required to deliver and store water and gas. The determination of the number of gas tanks includes a correction for ullage (the amount of gas that cannot be recovered from a tank after pressures equalize). For both $\mathrm{N}_{2}$ and $\mathrm{O}_{2}$ tank storage, a $0.5 \mathrm{~kg}$ per carrier ullage loss was assumed, as shown in Table 3 .

\section{Case Results and Mass Breakdown}

Under the assumptions defined in the previous sections, an assessment of logistics requirements was conducted for the two mission scenarios described in Section 2: a 60-day case using open-loop ECLSS, and a 1000-day case using partially closed ECLSS capabilities. The analysis provides insight into the mass and volume of logistics required to the support crew for each potential exploration mission scenario. For the openloop case, gas leakage is calculated assuming that the integrated stack includes two modules in addition to Orion (a habitable module and a logistics module). For the closed-loop case, the integrated stack includes the DSV and a second module representing a logistics carrier (no Orion present).

\section{Crewed Cis-Lunar Mission}

Table 5 and Table 6 provide a mass and volume breakdown, respectively, of the crew consumables requirements necessary to support 4 crewmembers on a 60 -day mission to cis-lunar space.

The Total CTBE Volume represents the volume to store all consumable goods, given the estimated packing density, assumptions given in Section 3. Given the relatively low packaging density assumed for all dry consumables - a maximum of $306 \mathrm{~kg} / \mathrm{m}^{3}$ - all CTB storage was volume limited. As a result a total of 71 CTBEs were required to store $839 \mathrm{~kg}$ of dry cargo. This equates to a total loaded mass of $950 \mathrm{~kg}$ given an overhead packaging mass of $1.56 \mathrm{~kg}$ per CTBE. The 71 CTBEs occupy a raw external volume of $3.76 \mathrm{~m}^{3}$. It should be noted that some additional margin should be expected in the total volume occupied by the packed CTBEs. In practical spacecraft applications, CTBE arrangement is limited by crew accessibility requirements and packing efficiency, leaving added volume between arranged CTBEs.

Table 5 - Logistics Mass Results for Cis-Lunar Mission

\begin{tabular}{|c|c|c|}
\hline \multicolumn{3}{|c|}{ CONSUMABLES } \\
\hline Item & $\begin{array}{c}\text { Total } \\
\text { Requirement (kg) }\end{array}$ & Notes \\
\hline Oxygen & 202 & $\begin{array}{l}\text { Crew consumption, } \\
\text { leakage/ullage }\end{array}$ \\
\hline Nitrogen & 6 & $\begin{array}{l}\text { Leakage/ullage assuming Orion + } \\
2 \text { modules }\end{array}$ \\
\hline Water & 723 & Open Loop \\
\hline Food & 439 & \\
\hline Personal Stowage & 100 & \\
\hline Operational Supplies & 80 & \\
\hline Personal Hygiene Kit & 7 & \\
\hline \begin{tabular}{|l|} 
Hygiene \\
Consumables
\end{tabular} & 19 & \\
\hline $\begin{array}{l}\text { Healthcare } \\
\text { Consumables }\end{array}$ & 22 & \\
\hline Wipes \& Towels & 47 & \\
\hline Trash Bags & 3 & \\
\hline Clothes & 53 & \\
\hline WC - fecal canisters & 54 & \\
\hline WC - urine prefilter & 15 & \\
\hline TOTAL CONSUMABLES & 1770 & $\mathrm{~kg}$ \\
\hline \multicolumn{3}{|c|}{ CARRIERS/CONTAINERS } \\
\hline Item & $\begin{array}{c}\text { Total } \\
\text { Requirement (kg) }\end{array}$ & Notes \\
\hline CTBEs & 112 & 71.5 CTBES \\
\hline Rodnik Tank & 140 & 4 Rodnik tank at $35 \mathrm{~kg}$ \\
\hline O2 Tank & 449 & 6 COPV at $74.8 \mathrm{~kg}$ each \\
\hline N2 Tank & 75 & 1 COPV at $74.8 \mathrm{~kg}$ \\
\hline $\begin{array}{r}\text { TOTAL CONTAINER } \\
\text { MASS } \\
\end{array}$ & 776 & kg \\
\hline TOTAL MASS & 2546 & kg \\
\hline
\end{tabular}

The absence of a water recovery system in the open-loop habitat results in a $723 \mathrm{~kg}$ water requirement to support all hygiene, flush, drink, medical, and rehydration activities. Nitrogen requirements, totaling $6 \mathrm{~kg}$, include losses due to pressurized volume leakage and air lost via the Orion swing bed of $0.76 \mathrm{~kg}$ and $5.16 \mathrm{~kg}$ respectively, along with $0.5 \mathrm{~kg}$ of tank ullage (one tank). Oxygen requirements consist of $197 \mathrm{~kg}$ for 4-crew metabolic requirements, $2.5 \mathrm{~kg}$ of swing bed/leakage losses, and $3 \mathrm{~kg}$ of tank ullage (six tanks). 
Table 6 - Logistics Volume Results for Cis-Lunar Mission

\begin{tabular}{|c|c|c|c|}
\hline \multicolumn{4}{|c|}{ Volume Dry Cargo } \\
\hline Case & $\begin{array}{c}\text { Usable Cargo } \\
\text { Masst (kg) }\end{array}$ & $\begin{array}{c}\text { Number of CTBs } \\
\text { Required }\end{array}$ & $\begin{array}{c}\text { Volume Required } \\
\left(\mathrm{m}^{3}\right)\end{array}$ \\
\hline 60 Day, 4 Crew & 838.4 & 71.5 & 3.79 \\
\hline \multicolumn{4}{|c|}{ † Does not include bag FSE + Foam } \\
\hline \multicolumn{4}{|l|}{ Volume of 1 CTB: } \\
\hline \multicolumn{4}{|c|}{ Volume of Water Tanks } \\
\hline Type of Tank & $\begin{array}{c}\text { Volume of } \\
\text { One Tank }\left(\mathrm{m}^{3}\right)\end{array}$ & $\begin{array}{c}\text { Total Number of } \\
\text { Tanks }\end{array}$ & $\begin{array}{l}\text { Total Volume } \\
\text { Required }\left(\mathrm{m}^{3}\right)\end{array}$ \\
\hline Water & 0.21 & 4 & 0.84 \\
\hline \multicolumn{4}{|c|}{ ISS NORS Tank Volume } \\
\hline Gas Carrier & Volume $\left(\mathrm{m}^{3}\right)$ & $\begin{array}{c}\text { Total Number of } \\
\text { Tanks }\end{array}$ & $\begin{array}{c}\text { Total Tank Volume } \\
\left(\mathrm{m}^{3}\right)\end{array}$ \\
\hline $\operatorname{COPV}\left(\mathrm{O}_{2}\right)$ & 0.39 & 6 & 2.34 \\
\hline $\operatorname{COPV}\left(\mathrm{N}_{2}\right)$ & 0.39 & 1 & 0.39 \\
\hline & & & 2.73 \\
\hline & & Total Volume & 7.36 \\
\hline
\end{tabular}

Notes:

NORS Tanks fly up in FSE that take up volume equivalent to an M-01 bag NORS Tanks pressurized at $6000 \mathrm{psi}$

Fluid and gas carrier requirements are also given in Table 6. Use of Rodnik-type carriers for water results in a four tank requirement for a total of $140 \mathrm{~kg}$ of tank mass. Delivery of nitrogen requires a single $75 \mathrm{~kg}$ tank while oxygen requires six tanks totaling $449 \mathrm{~kg}$. Overall, a total of $664 \mathrm{~kg}$ worth of carriers was necessary to deliver the required $931 \mathrm{~kg} \mathrm{H}_{2} \mathrm{O}, \mathrm{O}_{2}$, and $\mathrm{N}_{2}$ load.

The overall mass breakdown for the Cis-lunar case, including overhead, is provided in Figure 1.

The results show that such mission scenario would require $2,546 \mathrm{~kg}$ and $\sim 7.4 \mathrm{~m}^{3}$ allocated to the consumables and crew provisions needed to sustain the crew. Even at such a relatively short mission duration, the logistics require a considerable amount of volume that must be taken into account since the early mission concept design stages.

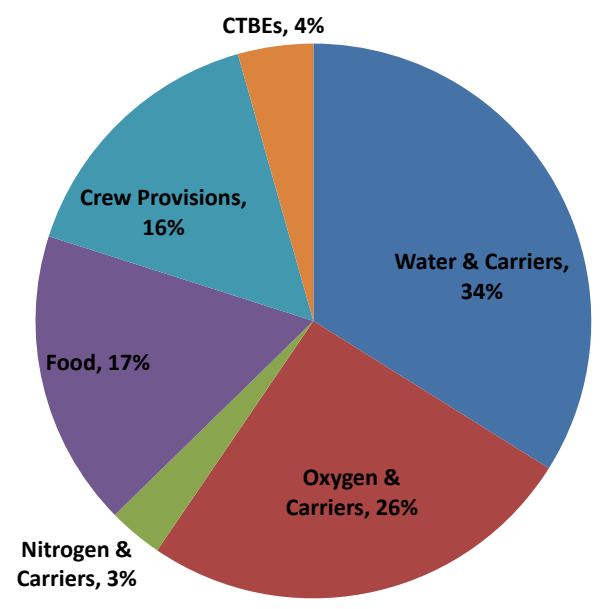

Figure 1 - Mass Breakdown for Cis-Lunar Mission

\section{Crewed Mars Mission}

Mass results for the crew consumable needs for the 1000-day Mars destination mission are given in Table 7. Results are broken out by mission phase, with 600 days of consumables allocated for transit periods, 400 days for Mars vicinity operations, and 30 days of contingency. As discussed in Section 2, current mission architectures assume the transit habitat carries complete survival capabilities for the entirety of the mission duration in the case that pre-emplaced Mars assets are unavailable in Mars vicinity. 30 days of contingency consumables are included in an open-loop configuration to cover periods of system downtime/repair and to allow for slight growth in the crewed mission duration.

Table 7 - Crew Consumables Mass Results for Mars Mission

\begin{tabular}{|c|c|c|c|c|}
\hline \multirow[t]{2}{*}{ Item } & \multicolumn{4}{|c|}{ Mass Required (kg) } \\
\hline & $\begin{array}{c}\text { 600-Day } \\
\text { Transit }\end{array}$ & $\begin{array}{c}\text { 400-Day } \\
\text { Mars } \\
\text { Vicinity }\end{array}$ & $\begin{array}{c}\text { 30-Day } \\
\text { Conting } \\
\text { ency }\end{array}$ & Total \\
\hline Oxygen & - & - & 99 & 99 \\
\hline Nitrogen & 4 & 3 & 1 & 8 \\
\hline Water & - & - & 362 & 362 \\
\hline Food & 4,394 & 2,930 & 220 & 7,544 \\
\hline $\begin{array}{l}\text { Personal } \\
\text { Stowage }\end{array}$ & 200 & - & - & 200 \\
\hline $\begin{array}{c}\text { Operational } \\
\text { Supplies }\end{array}$ & 100 & - & - & 100 \\
\hline $\begin{array}{c}\text { Personal } \\
\text { Hygiene Kit }\end{array}$ & 29 & 22 & - & 51 \\
\hline $\begin{array}{c}\text { Hygiene } \\
\text { Consumables }\end{array}$ & 190 & 126 & 10 & 326 \\
\hline $\begin{array}{c}\text { Healthcare } \\
\text { Consumables }\end{array}$ & 216 & 144 & 11 & 371 \\
\hline $\begin{array}{c}\text { Wipes \& } \\
\text { Towels }\end{array}$ & 468 & 312 & 23 & 803 \\
\hline Trash Bags & 26 & 18 & 1 & 45 \\
\hline Clothes & 528 & 352 & 26 & 906 \\
\hline $\begin{array}{c}\text { WC - fecal } \\
\text { canisters }\end{array}$ & 540 & 360 & 27 & 927 \\
\hline $\begin{array}{l}\text { WC - urine } \\
\text { prefilters }\end{array}$ & 150 & 100 & 8 & 258 \\
\hline Total Mass & 6,845 & 4,367 & 788 & 12,000 \\
\hline
\end{tabular}

Volumetric requirements for the dry goods, along with total CTBE loading and volumes, are given in Table 8. 
Table 8 - Dry Goods Packing Requirements

\begin{tabular}{|c|c|c|c|c|}
\hline & $\begin{array}{c}\text { 600-Day } \\
\text { Transit }\end{array}$ & $\begin{array}{c}\text { 400-Day } \\
\text { Mars } \\
\text { Vicinity }\end{array}$ & $\begin{array}{c}\text { 30-Day } \\
\text { Contingency }\end{array}$ & Total \\
\hline $\begin{array}{c}\text { Total } \\
\text { Consumables } \\
\text { Mass (kg) }\end{array}$ & 6,841 & 4,364 & 326 & $\mathbf{1 1 , 5 3 1}$ \\
\hline $\begin{array}{c}\text { CTBE Mass (kg) } \\
\text { Total Loaded } \\
\text { Mass (kg) }\end{array}$ & 7,731 & 4,930 & 369 & $\mathbf{1 3 , 0 3 0}$ \\
\hline $\begin{array}{c}\text { Total CTBEs } \\
\text { Required }\end{array}$ & 570.5 & 363 & 27.5 & $\mathbf{9 6 1}$ \\
\hline $\begin{array}{c}\text { Total CTBEs } \\
\left.\text { Volume (m }{ }^{3}\right)\end{array}$ & 30.2 & 19.2 & 1.5 & $\mathbf{5 0 . 9}$ \\
\hline
\end{tabular}

CTBE loading is given in total as well as broken out by transit, Mars vicinity, and contingency cargo allocations. Including contingency, a total of $961 \mathrm{CTBEs}$ are required to store $11,531 \mathrm{~kg}$ of dry consumables and crew provisions. This results in a total loaded CTBE mass of $13,030 \mathrm{~kg}$, occupying a raw external volume of $50.9 \mathrm{~m}^{3}$, excluding volumetric growth associated with arrangement constraints.

Table 9 provides fluid and gas requirements for the 1,000 day mission, along with associated carrier masses and total volume.

Table 9 - Fluid and Gas Mass/Volume Requirements for Mars Mission

\begin{tabular}{|c|c|c|c|c|c|}
\hline Fluid/Gas & $\begin{array}{c}\text { Mass } \\
\text { Required } \\
(\mathbf{k g})\end{array}$ & $\begin{array}{c}\text { \# Carriers } \\
\text { Required }\end{array}$ & $\begin{array}{c}\text { Total Fluid } \\
\text { Mass w } \\
\text { Ullage } \mathbf{( k g )}\end{array}$ & $\begin{array}{c}\text { Total } \\
\text { Carrier } \\
\text { Mass } \\
(\mathbf{k g})\end{array}$ & $\begin{array}{c}\text { Total } \\
\text { Carrier } \\
\text { Volume } \\
\left(\mathbf{m}^{\mathbf{3}}\right)\end{array}$ \\
\hline $\mathrm{H}_{2} \mathrm{O}$ & 362 & 2 & 362 & 70 & 0.4 \\
\hline $\mathrm{O}_{2}$ & 99 & 3 & 101 & 225 & 1.2 \\
\hline $\mathrm{N}_{2}$ & 8 & 1 & 9 & 75 & 0.4 \\
\hline Total & 469 & & 472 & 370 & $\mathbf{2 . 0}$ \\
\hline
\end{tabular}

Water reclamation from $\mathrm{H}_{2} \mathrm{O}$ contained within food promotes water-rich operating conditions for the partially closed ECLSS. As such, only 30 days of contingency water and oxygen were required to be delivered with the habitat, resulting in $362 \mathrm{~kg}$ and $99 \mathrm{~kg}$ of water and oxygen required respectively. $9 \mathrm{~kg}$ of nitrogen was required due to expected pressurized volume leakage.

Figure 2 provides the mass breakdown for the representative Mars destination mission.

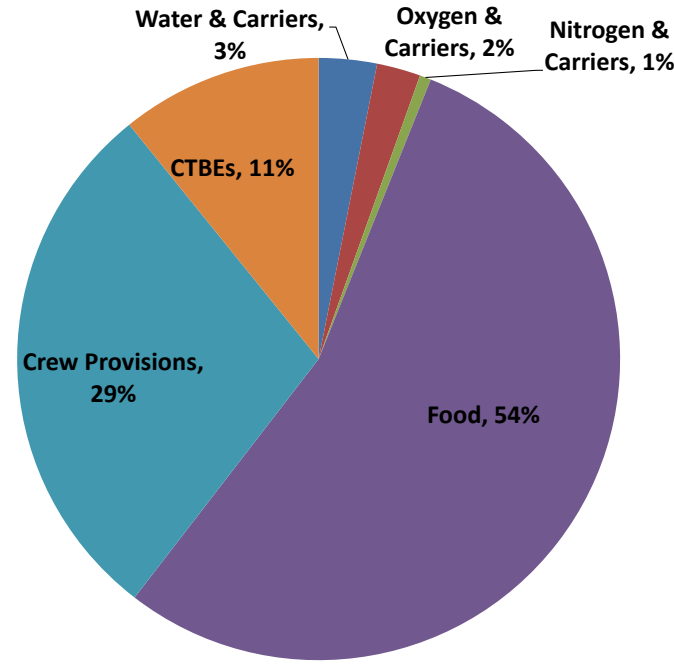
Figure 2 - Mass Breakdown for Mars Destination
Mission

\section{LOGISTICS OPPORTUNITIES \& THREATS}

The results of the logistics analysis indicate that there are several areas that could be investigated for opportunities to reduce total logistics mass. These opportunities are listed below.

\section{Food}

For this feasibility study, $1.831 \mathrm{~kg} / \mathrm{crew} /$ day was used as the food consumption rate based on the BVAD and ISS experience. This rate is based on current packaging methods in which each food item is packaged separately. The average metabolic requirement, in turn, is $1.5 \mathrm{~kg} / \mathrm{crew} / \mathrm{day}$, resulting in $\sim 0.331 \mathrm{~kg}$ available for reduction via packaging optimization. It is possible that a portion of this added mass could be eliminated through alternate packaging methods. Such methods must be explored to determine whether the rate can be reduced.

In addition, it may be possible to reduce total logistics requirements through the application of food with a lower hydration level than is currently assumed. Current ISS food is already partially dehydrated and palatability issues have limited further dehydration. If those issues could be overcome, it would be possible to reduce the total food mass. Because the closed-loop ECLSS system produces a net surplus of water, some amount of additional water that would be required to rehydrate the food will not increase the overall logistics requirements. However, at some point additional reductions in food mass must be offset by additional water requirements or a greater degree of ECLSS closure.

\section{CTBS}

CTBs are designed to withstand launch loads while safely delivering a wide array of items, including cargo densities as high as $560 \mathrm{~kg} / \mathrm{m}^{3}$, which represent the maximum cargo load for a strapped CTB. Most of the logistics items in this study 
have a lower density, including food (assumed at $306 \mathrm{~kg} / \mathrm{m}^{3}$ ) clothes, wipes, hygiene, trash bags, etc. Thus, CTBs are overdesigned to deliver these items. Custom-designed bags for lower-density cargo would result in mass savings. In addition, it might also be possible to transfer logistics to much lower mass containment system once the cargo is in LEO. The heavier CTBs could then be discarded, repurposed, or reused. Concepts should be pursued, and testing could be achieved on cargo delivery missions to ISS.

\section{Fecal Canisters}

For this feasibility study, $0.9 \mathrm{~kg} /$ day was used as the fecal canister rate based on Orion values. Current mission concept scenarios assume that the canisters are used to collect and store fecal waste. Multiple crew uses are stored in a single canister, which is then removed periodically once it is full. The canister is used to safely store the fecal waste after collection. Processing waste instead of storing it in the original canister may be an opportunity to use fewer disposable canisters. In addition, dry waste would be safer to store in bags or other lightweight containers. An assessment of other options and designs should be pursued to determine an optimal solution.

\section{Clothing}

For this feasibility study, $0.22 \mathrm{~kg} / \mathrm{crew} /$ day was used as the clothing rate based on recent ISS data. This rate is based on disposable clothes and no laundry system. A laundry system could be used to substantially reduce the total mass required, allowing clothes to be reused over the mission. However, in order to fully assess potential mass savings, the total impacts of adding a laundry system must be evaluated. This includes the mass of the laundry itself, including spares and maintenance items. If the laundry is a water-based system, the added load and resultant system sizing must also be evaluated for the water processor. Other proposed laundry technologies, utilizing microwaves and/or vacuum, also show promise.

The clothing consumption rate could also be reduced via reusable clothing. An integrated assessment that includes laundry systems and reusable clothing could be pursued to determine an optimal solution.

\section{Other Opportunities}

In addition to the previously identified candidates, an assessment of containers used for water and gas storage could result in mass savings. The current study assumes Rodnik tanks for water, which have a mass of $35 \mathrm{~kg}$ and can hold up to $210 \mathrm{~L}$. For gases, this study assumes the use of COPVs with a mass of $74.8 \mathrm{~kg}$ and a capacity of $38.1 \mathrm{~kg}$ of $\mathrm{O}_{2}$ or $28.7 \mathrm{~kg}$ of $\mathrm{N}_{2}$. Other containment options, including the use of integral tanks, should be evaluated to determine whether a more efficient solution is possible.
In addition to potential opportunities for mass and volume savings, there are items that could represent threats due to the assumptions of this study. These threats are listed below.

\section{Food Expiration}

Useful stored lifetime for food varies depending on the food type. Deep-space missions such as the Mars transit vehicle concept could require means to extend food lifetime, such as a freezer. This would result in a substantial increase in total spacecraft mass and volume. Methods to address this threat must be assessed during the early mission concept stages.

\section{EVA Consumables}

EVA operations tend to have large requirements for water and gas consumables. Any significant rate of EVAs during these missions could result in a substantial increase in total requirements.

\section{CTB Packing Density}

The current study does not include storage efficiency to address CTB arrangement and accessibility during the mission. This could increase the CTB stowed volume by as much as $30 \%$. Mission concept studies should assess the additional volume required to enable crew access to the logistics based on the mission profile.

\section{Conclusions}

An assessment of logistics requirements for future exploration missions suggests that the consumables required to support a crew for extended durations in deep space will be substantial. The large mass and volume requirements predicted for both a 60-day cis-lunar and 1000-day Mars destination mission suggest that logistics requirements must be considered during the design of any cis-lunar or Mars missions.

Food allocations were one of the primary drivers of total logistics mass, given the direct scaling with both crew size and mission duration. Food mass constituted $52 \%$ and $66 \%$ of the total dry consumables masses for the cis-lunar and Mars missions respectively.

Two areas of particular interest for reducing total food mass, lowered hydration rate and reduced packaging mass may present some opportunities for improvement, although the benefits will likely be limited. Reduced hydration rates below the $28 \%$ used on ISS may compromise palatability. Lower levels of food hydration will also limit ECLSS water yield, such that, at some point, any reduced food mass will be offset by increased water delivery requirements or increased ECLSS closure. Current packaging methods for ISS meals allow for excess food and packaging mass. Improved containment systems could potentially be used to reduce this mass.

Clothing also was a major driver of total consumables mass. As such, the inclusion of a laundry system may provide 
substantial benefit. Conventional water-based systems would likely require substantial growth in the ECLSS system. However there is potential that new technologies, such as microwave and vacuum based laundry systems could reduce total mass without increasing water usage.

CTBs and fecal canisters were major components of the total consumables mass and as such represent ideal candidates for mass optimization studies.

There was a dramatic difference in fluid and gas requirements for the two mission architectures evaluated for this paper. The open-loop ECLSS evaluated as part of the cis-lunar case resulted in large requirements of $\mathrm{H}_{2} \mathrm{O}, \mathrm{O}_{2}$, and $\mathrm{N}_{2}$. In this case $67 \%$ of the total consumables mass was allocated to fluids and gasses and their respective carriers. The partially closed ECLSS utilized in the Mars destination mission required a substantially smaller amount of water and gas, with only $6 \%$ of the total consumables mass attributed to $\mathrm{H}_{2} \mathrm{O}, \mathrm{O}_{2}, \mathrm{~N}_{2}$, and carriers.

The assessment results for the 1000-day mission suggest that increases in ECLSS performance above the currently assumed level of closure may have limited benefit in future exploration missions. The assumed DSV ECLSS continuously produces excess water due to continuous introduction of water into the system in food. This result may, however, change with the assessment of EVA requirements. EVA sublimator and drink requirements are substantial. Depending on the assumed EVA rate, water consumption requirements may increase to a degree such that further improvements in ECLSS closure may provide real benefit. It should also be noted that increased ECLSS closure may prove beneficial if palatable food can be developed with extremely low hydration levels.

While the total consumables requirements presented in this assessment are substantial, it must be reiterated that an analysis of sparing and maintenance requirements are not included in this assessment. Accounting for sparing and maintenance requirements will likely result in logistics payloads that are markedly greater than those presented in this study. Further studies must integrate these results to provide a more comprehensive estimate of the total logistics payloads required for crewed deep space exploration.

Numerous uncertainties exist in exploration logistics performance that must be addressed in future studies. Food longevity limits may be a concern for Mars-class missions, requiring additional food management technologies such as integrated freezers or long-duration packaging that may increase total mass. Large logistics payloads may also present challenges with respect to cargo storage and arrangement, requiring conservative $\mathrm{CTB}$ positioning to ensure crew accessibility.

\section{ACKNOWLEDGEMENTS}

The authors acknowledge Imelda Stambaugh (NASA Johnson Space Center), Molly Anderson (NASA Johnson
Space Center), Michael Ewert (NASA Johnson Space Center), and Robert Bagdigian (NASA Marshall Space Flight Center) for their insight, expertise, and countless hours of discussions and telecons to help produce the data contained in this paper.

\section{REFERENCES}

[1] http://www.nasa.gov/mission_pages/asteroids/initiative/

[2] Craig, D., Herrmann, N., and Troutman, P., "The Evolvable Mars Campaign - Study Status," 2015 IEEE Aerospace Conference, Big Sky, MT, 2015.

[3] Hanford, Anthony J., "Advanced Life Support Baseline Values and Assumptions Document," NASA-CR-2004208941, 2004.

[4] "Human Integration Design Handbook," NASA-SP-20103407, 2010.

\section{BIOGRAPHY}

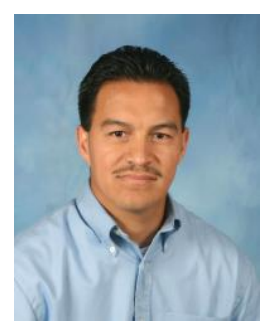

Pedro Lopez Jr. received his B.S. and M.S. in Mechanical Engineering from the University of Texas - Pan American in 2000 and 2003, respectively, and his Ph.D. in Mechanical Engineering from Rice University in 2014. He joined NASA JSC in 2007. He currently works as a Systems Engineering \& Integration (SE\&I) Lead for the Advanced Mission Development Group (AMDG), designing concepts for various potential mission scenarios including the Asteroid Redirect Crewed Mission (ARCM). Prior to this, he worked as an ISS ATCS Lead. He started his JSC career working as the Aerothermodynamics and Aerodynamics Technical Manager for the Space Shuttle Program SE\&I Office, while also serving as the Debris Integration Group (DIG) Deputy Manager.

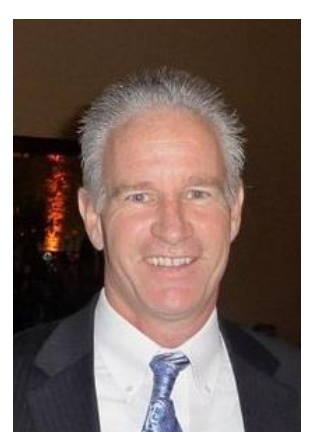

Eric Demarest Schultz received his B.S. in Mechanical Engineering from Lamar University in 1985. Mr. Schultz currently works as the International Space Station (ISS) Consumables and Food Lead, assessing, integrating, and manifesting critical ISS crew life support systems consumables and food, while also conducting special logistical studies for the Advanced Mission Development Group (AMDG). Mr. Schultz is the lead for the ISS Plug-in-Plan (IPiP), managing a contractor team that identifies requirements, replacement hardware, and new power sources for connecting portable hardware to be used on the ISS. Mr. Schultz started his aerospace career designing launch times that support desired Space Shuttle requirements for United Space Alliance. Mr. Schultz. transitioned over to the Space Station Mission Operations Directorate in 1991 where he established operational 
concepts for early Space Station Trajectory Operations (TOPO) group and developed trajectory debris avoidance processes for ISS. In 1994, Mr. Schultz transferred to the ISS Program, Mission Integration and Operations Office, where he created Generic Ground rules and Constraints, and Increment Definition and Requirements for the ISS. Mr. Schultz began his NASA JSC career in 2001 working as a Systems Engineer and Consumables Analysis Lead in the Vehicle Integrated, Performance, and Resources (VIPER) group.

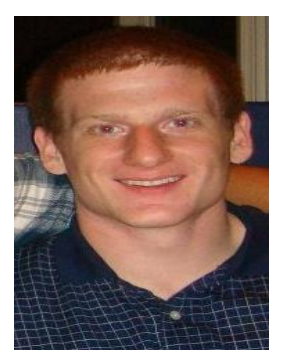

Bryan Mattfeld received bachelor's degrees both in Aerospace Engineering and Mathematics from Virginia Polytechnic and State University in Blacksburg, Virginia in 2013. He has 4 years experience in space systems engineering and risk analysis. His work includes the development and analysis of space systems and mission design models. He currently works for Binera, Inc. in Silver Spring, Maryland and is an AIAA member.

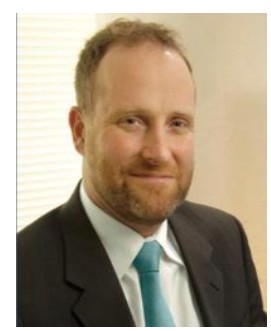

Chel Stromgren currently serves as the Chief Scientist of Binera, Inc. In this role, Mr. Stromgren leads the development of probability and riskbased strategic models and strategic analysis of complex system development. $M r$. Stromgren has supported NASA in the analysis of Space Shuttle and International Space Station operations in the post-Columbia environment and has led the development of strategic campaign models for the lunar exploration initiatives. He holds a Bachelor of Science degree in Marine Engineering and Naval Architecture from the Webb Institute and a Master of Science degree in Systems Management from the Massachusetts Institute of Technology.

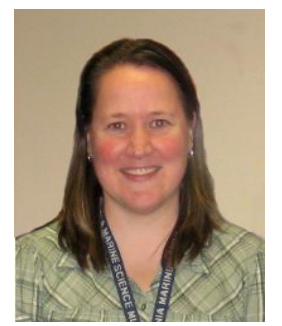

Kandyce Goodliff is an aerospace engineer at NASA Langley Research Center in Hampton, VA, with the Space Mission Analysis Branch (SMAB). Her primary roles as a systems analyst for $S M A B$ are conceptual design and sizing of human and robotic spacecraft, mission and spacecraft analysis, and campaign analysis for human exploration. She has a Bachelor of Science in Aerospace Engineering from EmbryRiddle Aeronautical University and a Master of Science in Mechanical Engineering from the George Washington University. 